\title{
Prevalence of marijuana use in pregnant women with concurrent opioid use disorder or alcohol use in pregnancy
}

Kimberly Page ${ }^{1 *} \mathbb{D}$, Cristina Murray-Krezan ${ }^{1}$, Lawrence Leemann ${ }^{2,3}$, Mary Carmody $^{1}$, Julia M. Stephen ${ }^{4}$ and Ludmila N. Bakhireva 1,2,5

\begin{abstract}
Background: A quarter of pregnant women use alcohol, 6.5/1000 deliveries are affected by opioid use disorder $(\mathrm{OUD})$, and the prevalence of cannabis use in pregnant women is increasing. However, marijuana co-exposure in polysubstance-using women is not well described.
\end{abstract}

Methods: The well-characterized ENRICH-1 cohort $(n=251)$, which focused on the effects of two primary exposures of interest-opioids and alcohol, was used to (1) estimate the prevalence/frequency of marijuana use in those with OUD and/or alcohol use, and (2) examined correlates of marijuana use. Participants were classified into an OUD group $(n=125)$, Alcohol group $(n=69)$, and concurrent OUD and Alcohol (OUD + Alcohol) group $(n=57)$. Self-report and biomarkers ascertained substance use. Multivariable logistic regression identified correlates of marijuana use.

Results: The prevalence of any marijuana use in pregnancy was 43.2\%, 52.6\%, and 46.4\% in the OUD, OUD + Alcohol, and Alcohol groups, respectively. Correspondingly, weekly or daily use was reported by $19.4 \%, 21.0 \%$, and $24.6 \%$ of participants. In the OUD and OUD + Alcohol groups, the proportion of women using marijuana was significantly higher in those taking buprenorphine (45.8\% and 58.3\%, respectively) compared to women using methadone (37.5\% and $42.9 \%$, respectively). Mean maternal age was lower in women who used marijuana in all three groups compared to non-marijuana users. Independent correlates of marijuana use (controlling for group, race/ethnicity, education, and smoking) were maternal age (adjusted Odds Ratio (aOR) per 5-year increment 0.61; (95\% Cl 0.47, 0.79)), and polysubstance use (aOR 2.02; $95 \% \mathrm{Cl} 1.11$, 3.67). There was a significant interaction between partnership status and group: among women who were not in a partnership, those in the OUD and OUD + Alcohol groups had lower odds of marijuana use relative to the Alcohol group. For women in the Alcohol group, partnered women had lower odds of marijuana use than un-partnered women (aOR 0.12; $95 \% \mathrm{Cl}: 0.02,0.68)$.

Conclusions: Results indicate a relatively high prevalence and frequency of marijuana use in pregnant women being treated for OUD and/or women consuming alcohol while pregnant. These results highlight the need for ongoing risk reduction strategies addressing marijuana use for pregnant women receiving OUD treatment and those with alcohol exposure.

Keywords: Alcohol, Cannabis, Marijuana, Opioids, Pregnancy

\footnotetext{
*Correspondence: pagek@salud.unm.edu

${ }^{1}$ Division of Epidemiology, Biostatistics and Preventive Medicine,

Department of Internal Medicine, School of Medicine, University of New Mexico MSC 10 5550, Albuquerque, NM 87131, USA

Full list of author information is available at the end of the article
}

\section{Introduction}

The opioid epidemic in the U.S. has affected people across the lifespan, including pregnant women and newborn children. In 2014, as many as $22.8 \%$ of Medicaid-enrolled original author(s) and the source, provide a link to the Creative Commons licence, and indicate if changes were made. The images or other third party material in this article are included in the article's Creative Commons licence, unless indicated otherwise in a credit line to the material. If material is not included in the article's Creative Commons licence and your intended use is not permitted by statutory regulation or exceeds the permitted use, you will need to obtain permission directly from the copyright holder. To view a copy of this licence, visit http://creativecommons.org/licenses/by/4.0/. The Creative Commons Public Domain Dedication waiver (http://creativeco mmons.org/publicdomain/zero/1.0/) applies to the data made available in this article, unless otherwise stated in a credit line to the data. 
pregnant women used prescription opioids during pregnancy [1]. Recent estimates demonstrated that more than $5 \%$ of pregnant women reported non-medical use of opioids in the past year [2]. The prevalence of OUD in pregnant women increased 333\% between 1999 and 2014 to 6.5/1000 deliveries [3]. In some states (i.e., West Virginia, Vermont), the prevalence of OUD is more than 30/1,000 hospital deliveries, with New Mexico also experiencing high rates at 14.8/1000 [3, 4].

Numerous studies have demonstrated associations between prenatal opioid exposure and intrauterine growth restriction (IUGR), preterm delivery, and stillbirth [5]. It is unclear if prenatal opioid exposure, medications for the treatment of OUD (MOUD), neonatal opioid withdrawal syndrome (NOWS), and/or treatment for NOWS are associated with poor long-term neurodevelopmental outcomes or if adverse outcomes are primarily driven by adverse pre- and postnatal environmental factors. The MOTHER trial [6] and our earlier results from the ENRICH cohort [7] were mostly reassuring, showing few or no effects on early childhood neurodevelopmental outcomes. A recent study demonstrated that infants with NOWS are at increased risk of unplanned healthcare utilization during the first year of life [8] A key challenge in assessing obstetric and neonatal outcomes is the need to fully account for the effects of polydrug use, i.e., co-exposure with marijuana, alcohol, stimulants, or other substances.

Among the most common co-exposures, prenatal alcohol and tobacco are associated with adverse neurodevelopmental outcomes for the offspring $[9,10]$. We demonstrated earlier that almost $25 \%$ of pregnant women with OUD reported binge drinking, and $85.8 \%$ reported tobacco use [10]. There is also emerging evidence showing prenatal marijuana exposure may be associated with adverse perinatal outcomes, including the risk of preterm birth, growth restriction, increased neonatal intensive care unit admission, and potential adverse neurodevelopmental outcomes [11-14]. While a retrospective cohort study of 191 maternal-infant dyads exposed to buprenorphine during pregnancy did not find any significant associations between the third-trimester marijuana use and adverse perinatal outcomes, marijuana co-exposure was associated with more severe NOWS [15].

The widespread use of medical marijuana and increasing legalization of recreational marijuana have been accompanied by increased reporting of its use among women of reproductive age $[16,17]$. The National Survey on Drug Use and Health (NSDUH) demonstrated a significant increase in marijuana use in reported previous month use in both pregnant (from 3.4\% to $7.0 \%$ ) and non-pregnant women of reproductive age (from $6.8 \%$ to 11.2\%) between 2002 and 2017 [18]. The most notable increase in marijuana use was in the first trimester of pregnancy (from $5.7 \%$ to $12.1 \%$ ). Similarly, a cross-sectional study of pregnant women receiving prenatal care at Kaiser Permanente Northern California demonstrated the prevalence of any marijuana use increased from $2.0 \%$ to $3.4 \%$ between 2009 and 2017 [19]. Both studies also showed that the frequency of use substantially increased over time. In addition, in states with legalized medical marijuana, the rate of admissions for marijuana use in substance use treatment programs increased by more than fourfold in pregnant women [20]. However, the prevalence of marijuana use in pregnant women who receive care for opioid use disorder (OUD) or other substances, including alcohol, is not well characterized.

We conducted a secondary analysis of data obtained from pregnant women participating in a well-characterized cohort with primary exposure to MOUD and alcohol [21] to: (1) estimate the prevalence and frequency of marijuana use (by self-report and urine drug testing) in those with OUD and/or alcohol exposure and (2) examine correlates of marijuana in this cohort. Based on the existing literature, we hypothesized that (a) the prevalence of marijuana use will be higher in pregnant women who use opioids and/or alcohol in pregnancy compared to the national estimate from the general obstetric population; (b) prevalence estimates of marijuana use will be comparable from self-report and urinalysis; (c) prevalence will be higher in younger women.

\section{Methods}

\section{Study design and population}

The data were obtained from the ENRICH-1 cohort at the University of New Mexico (UNM), described elsewhere [21]. In brief, the ENRICH-1 study evaluated the effects of prenatal substance use through four prospective visits: (1) a baseline prenatal visit; (2) hospitalization for labor and delivery; (3) 6 months postpartum, and (4) 20 months postpartum. Participants were recruited from UNM general prenatal care clinics and the Milagro clinic, which specializes in prenatal care for women with substance use disorders (SUD). ENRICH-1 eligibility criteria included: (1) the mother was $\geq 18$ years old; (2) a singleton pregnancy confirmed by ultrasound; (3) gestational age 12-35 weeks at enrollment; (4) intention to deliver at the UNM Hospital and remain in the Albuquerque metropolitan area for at least two years; and (5) the ability to provide written consent in English. Exclusion criteria were: (1) a fetal diagnosis of a major structural anomaly; (2) greater than occasional ( $>1$ positive urine drug screen (UDS) or self-report of greater than monthly) use of cocaine, crack cocaine, methamphetamines, or MDMA during the first trimester and any use of these substances during the second or third trimesters. 
The study was approved by the UNM Human Research Review Committee; all participants provided signed informed consent.

Based on data collected at the baseline visit, the participants were categorized into three groups based on the primary exposure of interest: the OUD group $(n=125)$, Alcohol group $(n=69)$, and concurrent OUD and Alcohol (OUD + Alcohol) group $(n=57)$. Unexposed controls enrolled in the ENRICH-1 cohort were excluded from this analysis since the prevalence of marijuana use could not be estimated in that group (which excluded any substance use). It is important to note that women enrolled in the ENRICH-1 cohort classified into the Alcohol group were not defined by the diagnosis of alcohol use disorder; they were identified from a general obstetrics population if they (a), scored $\geq 2$ on the AUDIT-C screening questionnaire, and consumed at least three drinks per week on average in the time between their last menstrual period (LMP) and pregnancy recognition, or (b) had $\geq 2$ binge episodes ( $\geq 4$ drinks/occasion) during the same interval.

\section{Characterization of prenatal substance use}

Alcohol use during pregnancy was assessed through both self-report and maternal ethanol biomarkers. Selfreported drinking was captured at the baseline visit through two Timeline Followback Calendars (TLFB): (1) 30 days centered on LMP (15 days before and after); (2) a 30-day period prior to the baseline visit. Quantity and frequency of reported alcohol on each day were converted into ounces of absolute alcohol per day (AA/day) [22]. In addition, five ethanol biomarkers were tested in maternal blood and urine collected at the baseline visit, including gamma-glutamyl transpeptidase, carbohydrate-deficient transferrin, phosphatidylethanol, urine ethyl glucuronide, and ethyl sulfate.

Substance use, including marijuana, was ascertained through both self-report and urine cannabinoid biomarkers (carboxy-THC). A structured questionnaire, based on the 2011 National Survey on Drug Use and Health [23], was administered to assess self-reported substance use between LMP and enrollment (on average, 23.0 gestational weeks). Street names of substances were provided to facilitate recall, and frequency of use was captured. Polysubstance use was coded as positive if women reported using at least one other substance, including stimulants, benzodiazepines, sedatives, prescription medications (Soma/Carisoprodol), or hallucinogens. In addition, a urine drug screen (UDS)-7 panel (amphetamines, barbiturates, benzodiazepines, cocaine, opiates, phencyclidine (PCP), cannabinoids/tetrahydrocannabinols (THC), and a nicotine metabolites panel (nicotine, cotinine, 3-hydroxycotinine, nornicotine, anabasine) were collected and analyzed at the U.S. Drug Testing Laboratory (Des Plaines, IL). Marijuana use was defined as any self-reported use between LMP and study enrollment or a positive result on UDS at the baseline visit. If participants were missing either self-report or UDS results for marijuana, prevalence estimates were based on the non-missing value. No participants were missing both values.

\section{Statistical analyses}

Participant characteristics and co-exposures were summarized with descriptive statistics. Overall, marijuana use and non-use groups were compared with independent two-sample tests of means using a $t$ test or Wilcoxon rank-sum test for normally and non-normally distributed data, respectively. Differences in categorical variables across the two groups were assessed with $\chi^{2}$ or Fisher's exact tests, as appropriate. To compare marijuana use among the three exposure groups, independent logistic regression models including group, characteristic, and an interaction between the two were fit to the data. The interaction terms from these models were assessed for differential marijuana use across the groups by demographic characteristics. A multivariable logistic regression model was fitted to marijuana use which included group as an independent variable and other covariates found to be associated with marijuana use in bivariate analyses, those hypothesized to be associated a priori (i.e., using other substances), and known or potential confounders (i.e., age, ethnicity, race, educational status, partnership status, and tobacco use during pregnancy). Interaction terms were added to the model based on findings of differential effects of marijuana use across the groups in the analyses of characteristics and co-exposures previously described (i.e., group $\times$ marital status). Adjusted odds ratios (aOR) and corresponding 95\% confidence intervals $(95 \% \mathrm{CI})$ from the model were reported. All statistical analyses were performed in SAS 9.4 (SAS Institute, Cary, NC, 2012).

\section{Results}

The sample included a high proportion of ethnic/racial minorities with 68.5\% Hispanic/Latina and 6.4\% American Indian women (Table 1$)$. The majority $(83.3 \%)$ of participants were enrolled in Medicaid. The overall prevalence of any marijuana use was $46.2 \%$ ( $45.8 \%$ by selfreport and $24.0 \%$ by UDS). There were no differences at enrollment between marijuana users and non-users with respect to gestational age, partnership status, Hispanic ethnicity, race, attained educational level, employment status, or medical insurance type. Marijuana users were significantly more likely than non-users to be younger, to report the use of other substances, and to report higher 
Table 1 Sociodemographic characteristics and substance use in the overall sample and by marijuana exposure during pregnancy $(n=251)$

\begin{tabular}{|c|c|c|c|c|}
\hline \multirow[t]{3}{*}{ Characteristics } & \multirow{3}{*}{$\begin{array}{l}\text { Overall } \\
\text { Mean (SD) }\end{array}$} & \multicolumn{2}{|c|}{ Marijuana exposure } & \multirow{3}{*}{ p-value } \\
\hline & & \multirow{2}{*}{$\begin{array}{l}\text { Use }(n=116) \\
\text { Mean (SD) }\end{array}$} & \multirow{2}{*}{$\begin{array}{l}\text { Non-use }(n=135) \\
\text { Mean (SD) }\end{array}$} & \\
\hline & & & & \\
\hline Maternal age at enrollment (years) & $28.4(5.6)$ & $27.0(5.5)$ & $29.5(5.5)$ & $<0.001^{1}$ \\
\hline \multirow[t]{2}{*}{ Gestational age at enrollment (weeks) } & $23.0(7.1)$ & $22.4(7.3)$ & $23.5(6.9)$ & $0.230^{1}$ \\
\hline & n (\%) & $n(\%)$ & $\mathrm{n}(\%)$ & p-value \\
\hline Partnership status ${ }^{\mathrm{a}}$ & & & & $0.132^{2}$ \\
\hline Single/separated/divorced/widowed & $108(43.0)$ & $56(48.3)$ & $52(38.5)$ & \\
\hline Married/cohabitating & $142(56.6)$ & $60(51.7)$ & $82(60.7)$ & \\
\hline Ethnicity: Hispanic/Latina & $172(68.5)$ & $82(70.7)$ & $90(66.7)$ & 0.494 \\
\hline Race & & & & $0.907^{3}$ \\
\hline African American & $4(1.6)$ & $1(0.9)$ & $3(2.2)$ & \\
\hline American Indian/Alaska Native & $16(6.4)$ & $7(6.0)$ & $9(6.7)$ & \\
\hline Multiracial/Other & $17(6.8)$ & $8(6.9)$ & $9(6.7)$ & \\
\hline White & $214(85.3)$ & $100(86.2)$ & $114(84.4)$ & \\
\hline Education level & & & & $0.570^{2}$ \\
\hline Less than high school & $62(24.7)$ & $29(25.0)$ & $33(24.4)$ & \\
\hline High school graduate or GED & $77(30.7)$ & $39(33.6)$ & $38(28.1)$ & \\
\hline Some college or higher & $112(44.6)$ & $48(41.4)$ & $64(47.4)$ & \\
\hline Employed (at enrollment) ${ }^{b}$ & $93(37.1)$ & $38(32.8)$ & $55(40.7)$ & $0.210^{2}$ \\
\hline Health insurance status & & & & $0.684^{2}$ \\
\hline Medicaid & $209(83.3)$ & 99 (85.3) & $110(81.5)$ & \\
\hline Employer-based insurance & $26(10.4)$ & $11(9.5)$ & $15(11.1)$ & \\
\hline Other $^{c}$ & $16(6.4)$ & $6(5.2)$ & $10(7.4)$ & \\
\hline Type of MOUD & & & & $0.486^{3}$ \\
\hline Methadone & $69(27.5)$ & $27(23.3)$ & $42(31.1)$ & \\
\hline Buprenorphine & $108(43.0)$ & $54(46.6)$ & $54(40.0)$ & \\
\hline Methadone and buprenorphine & $5(2.0)$ & $3(2.6)$ & $2(1.5)$ & \\
\hline \multicolumn{5}{|l|}{ Other opioid use $\mathrm{d}^{\mathrm{d}}$} \\
\hline Heroin & $76(30.3)$ & 39 (33.6) & $37(27.4)$ & $0.303^{2}$ \\
\hline Opioid analgesics & $60(23.9)$ & $32(27.6)$ & $28(20.7)$ & $0.217^{2}$ \\
\hline Opiates detected by UDS only & $4(1.6)$ & $3(2.6)$ & $1(0.7)$ & $0.338^{3}$ \\
\hline Polysubstance use $\mathrm{e}^{\mathrm{e}}$ & $91(36.3)$ & $52(44.8)$ & $39(28.9)$ & $0.009^{2}$ \\
\hline \multirow[t]{2}{*}{ Tobacco use } & $177(70.5)$ & $89(76.7)$ & $88(65.2)$ & $0.046^{2}$ \\
\hline & Mean (SD) & Mean (SD) & Mean (SD) & p-value \\
\hline Average ounces of alcohol per day, LMP to Visit $1^{f}$ & $0.4(1.2)$ & $0.6(1.5)$ & $0.3(1.0)$ & $0.027^{4}$ \\
\hline AUDIT score & $7.3(9.0)$ & $7.8(8.6)$ & $6.8(9.4)$ & $0.071^{4}$ \\
\hline
\end{tabular}

GED General Educational Development, MOUD medication for opioid use disorder, UDS urine drug screen, LMP last menstrual period

${ }^{a}$ One partnership status is missing in the marijuana non-use group

${ }^{b}$ One employment status is missing the marijuana use group

c "Other" includes lack of insurance or self-purchased

${ }^{d}$ Categories are not mutually exclusive

e Polysubstance use defined as using at least one other substance including: stimulants, benzodiazepines, sedatives, prescription medications (Soma/Carisoprodol), or hallucinogens

${ }^{f}$ Average absolute ounces of alcohol per day across two 30-day timeline follow-back (TLFB) calendars

${ }^{1}$ P-value obtained from the two-sample $t$ test

${ }^{2}$ P-value obtained from the chi-square test

${ }^{3}$ P-value obtained from the Fisher's exact test

${ }^{4} \mathrm{P}$-value obtained from the two-sample Wilcoxon rank sum test 
alcohol use in early pregnancy (Table 1 ). The prevalence of stimulants ( $26.7 \%$ vs. $17.8 \%)$, benzodiazepines $(23.3 \%$ vs. $14.8 \%$ ), sedatives ( $7.8 \%$ vs. $3.0 \%)$, and tobacco $(76.7 \%$ vs. $65.2 \%)$ was higher in marijuana users compared to non-users. No statistical differences between marijuana users and non-users were seen in self-reported heroin use (33.6\% vs. $27.4 \%)$, self-reported opioid analgesics ( $27.6 \%$ vs. $20.7 \%)$, nor for opiates detected only by UDS $(2.6 \%$ vs. $0.7 \% \%)$. The frequency of marijuana use is shown in Fig. 1. Among 135 women who denied using marijuana, $2(1.5 \%)$ had positive urine screen results, and of 114 women who reported marijuana use, 51 (44.7\%) had negative urine screen results. There were two participants with missing self-reports and nine participants with missing urine results, and these were presumed to be negative. Overall, women in the OUD group had the lowest prevalence of any marijuana use $(41.9 \%$ vs. $52.6 \%$ in the OUD + Alcohol group and 47.1\% in the Alcohol group). The use of marijuana at least weekly was most prevalent in the Alcohol group (25.0\%) in contrast to the two groups of women with OUD.

Comparisons of the prevalence of marijuana use by the sociodemographic characteristics in the three study groups are shown in Table 2. No differences were found in marijuana use between groups by sociodemographic characteristics with the exception of partnership status. A significant interaction between study group and partnership status was found with respect to marijuana use: the highest proportion of marijuana users was in the Alcohol group, with $85.7 \%$ of un-partnered women reporting marijuana use compared to $36.4 \%$ of partnered women. In the OUD + Alcohol group, the reverse pattern was observed. Namely, marijuana use was higher in the partnered women (61.5\%) compared to un-partnered women (45.2\%). (Fig. 2).

Table 3 shows prevalence of marijuana use by MOUD and other substance use in the three groups. All (100\%) women in the OUD and OUD + Alcohol groups were using prescribed methadone and/or buprenorphine. In the OUD group, under half (45.8\%) of women prescribed buprenorphine used marijuana, whereas over half (58.3\%) of women prescribed buprenorphine in the OUD + Alcohol group used marijuana, but this difference was not significant. Women who reported polysubstance use were more likely to report marijuana in all three groups (55.6\%, 58.6\%, and 58.8\% in the OUD, OUD+Alcohol, and Alcohol groups, respectively) relative to non-polydrug users. While a slightly higher proportion of women reporting heroin use in the OUD+Alcohol group used marijuana $(56.0 \%)$ in contrast to women who used heroin

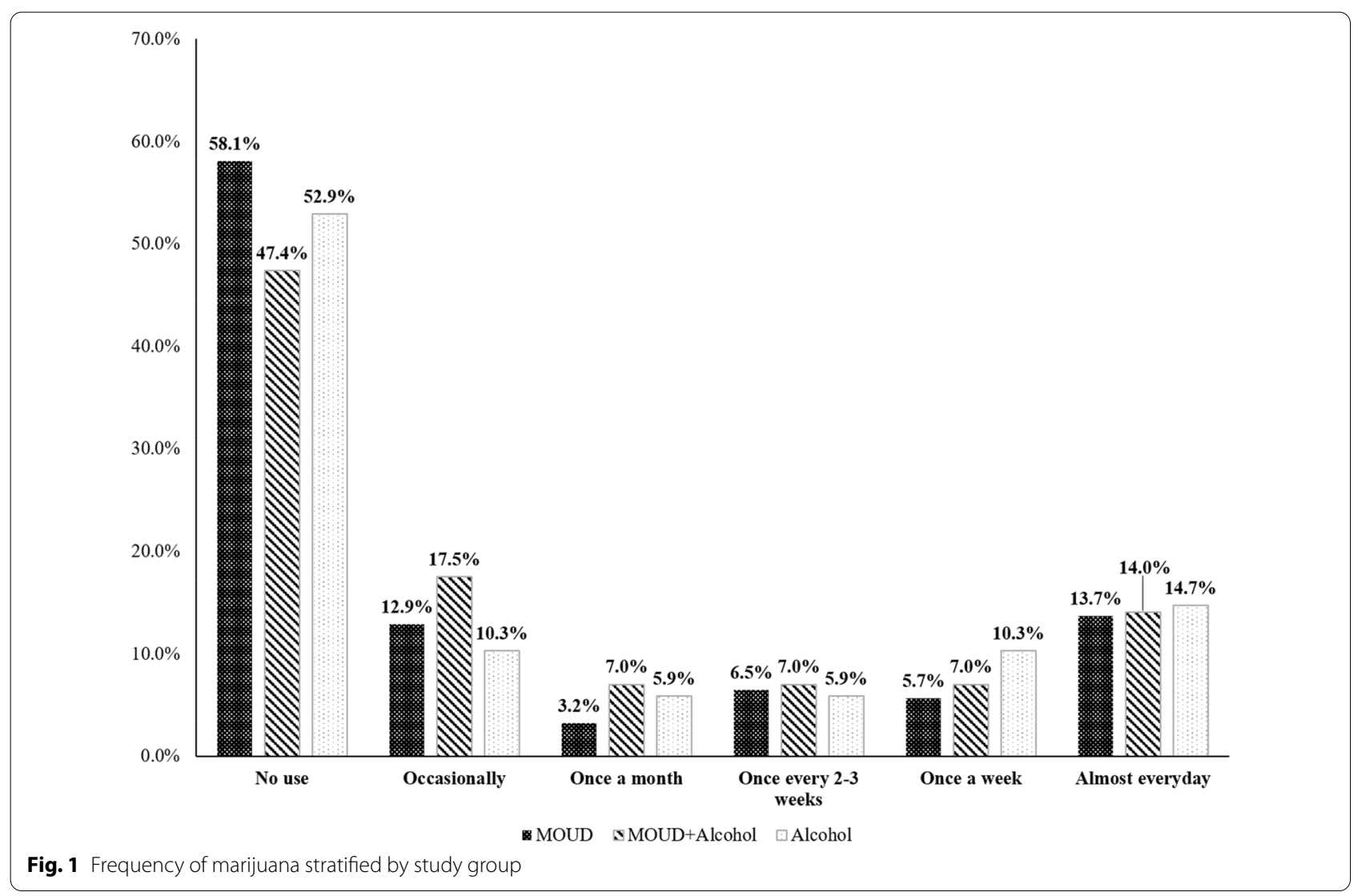


Table 2 Prevalence of marijuana use during pregnancy by sociodemographic characteristics stratified by study group use ( $N=251$ )

\begin{tabular}{|c|c|c|c|c|c|c|}
\hline \multirow[t]{3}{*}{ Characteristics } & \multicolumn{2}{|l|}{ OUD $(n=125)$} & \multicolumn{2}{|c|}{ OUD + alcohol $(n=57)$} & \multicolumn{2}{|l|}{ Alcohol $(n=69)$} \\
\hline & Marijuana use $(n=54)$ & $\begin{array}{l}\text { No } \\
\text { marijuana } \\
\text { use }(n=71)\end{array}$ & $\begin{array}{l}\text { Marijuana use } \\
(n=30)\end{array}$ & $\begin{array}{l}\text { No } \\
\text { Marijuana } \\
\text { use }(n=27)\end{array}$ & Marijuana use $(n=32)$ & $\begin{array}{l}\text { No } \\
\text { Marijuana } \\
\text { use }(n=37)\end{array}$ \\
\hline & Mean (SD) & Mean (SD) & Mean (SD) & Mean (SD) & Mean (SD) & Mean (SD) \\
\hline $\begin{array}{l}\text { Maternal age at enrollment } \\
\text { (years) }\end{array}$ & $27.0(5.9)$ & $29.2(5.3)$ & $25.8(4.3)$ & $29.0(5.2)$ & $28.2(5.6)$ & $30.5(6.2)$ \\
\hline \multirow{2}{*}{$\begin{array}{l}\text { Gestational age at enrollment } \\
\text { (weeks) }\end{array}$} & $20.7(6.6)$ & $22.6(6.6)$ & $23.9(7.7)$ & $22.5(7.3)$ & $23.8(7.7)$ & $25.9(6.9)$ \\
\hline & n (\%) & n (\%) & n (\%) & n (\%) & n (\%) & n (\%) \\
\hline \multicolumn{7}{|l|}{ Partnership status ${ }^{1, a}$} \\
\hline $\begin{array}{l}\text { Single/separated/divorced/ } \\
\text { widowed }\end{array}$ & $30(47.6)$ & $33(52.4)$ & $14(45.2)$ & $17(54.8)$ & $12(85.7)$ & $2(14.3)$ \\
\hline Married/cohabitating & $24(39.3)$ & $37(60.7)$ & $16(61.5)$ & $10(38.5)$ & $20(36.4)$ & $35(63.6)$ \\
\hline Ethnicity: Hispanic/Latina & $42(43.8)$ & $54(56.3)$ & $24(61.5)$ & $15(38.5)$ & $16(43.2)$ & $21(56.8)$ \\
\hline \multicolumn{7}{|l|}{ Race } \\
\hline African American & $1(100.0)$ & $0(0.0)$ & $0(0.0)$ & $2(100.0)$ & $0(0.0)$ & $1(100.0)$ \\
\hline American Indian/Alaska Native & $2(28.6)$ & $5(71.4)$ & $1(50.0)$ & $1(50.0)$ & $4(57.1)$ & $3(42.9)$ \\
\hline Multiracial/Other & $3(42.9)$ & $4(57.1)$ & $1(50.0)$ & $1(50.0)$ & $4(50.0)$ & $4(50.0)$ \\
\hline White & $48(43.6)$ & $62(56.4)$ & $28(54.9)$ & $23(45.1)$ & $24(45.3)$ & $29(54.7)$ \\
\hline \multicolumn{7}{|l|}{ Education level } \\
\hline Less than high school & $23(46.9)$ & $26(53.1)$ & $10(55.6)$ & $8(44.4)$ & $6(60.0)$ & $4(40.0)$ \\
\hline High school graduate or GED & $12(37.5)$ & $20(62.5)$ & $12(63.2)$ & $7(36.8)$ & $5(45.5)$ & $6(54.6)$ \\
\hline Some college or higher & $19(43.2)$ & $25(56.8)$ & $8(40.0)$ & $12(60.0)$ & $21(43.8)$ & $27(56.3)$ \\
\hline Employed (at enrollment) ${ }^{\mathrm{b}}$ & $13(33.3)$ & $26(66.7)$ & $6(66.7)$ & $3(33.3)$ & $19(42.2)$ & $26(57.8)$ \\
\hline \multicolumn{7}{|l|}{ Health insurance status } \\
\hline Medicaid & $50(42.4)$ & $68(57.6)$ & $29(54.7)$ & $24(45.3)$ & $20(52.6)$ & $18(47.4)$ \\
\hline Employer-based insurance & $3(60.0)$ & $2(40.0)$ & $1(50.0)$ & $1(50.0)$ & $7(36.8)$ & $12(63.2)$ \\
\hline Other ${ }^{c}$ & $1(50.0)$ & $1(50.0)$ & $0(0.0)$ & $2(100.0)$ & $5(41.7)$ & $7(58.3)$ \\
\hline
\end{tabular}

OUD opioid use disorder, GED General Educational Development

${ }^{1} p<0.01$ (Wald test from logistic regression model for the interaction between marital status and group classification)

a One subject in the OUD group did not report partnership status

${ }^{b}$ One subject in the Alcohol group did not report employment status

c "Other" includes lack of insurance or self-purchased

in the OUD group (49.0\%), the interaction was not significant. Marijuana use was similar in women who reported opioid analgesic use or for whom opiates were detected only by UDS in all groups.

After controlling for study group, ethnicity, race, education level, and tobacco use during pregnancy, independent correlates of marijuana use in all groups included maternal age-where marijuana use declined by 5 -year increments in age (aOR 0.61; 95\% CI: 0.47, 0.79) and polysubstance use-marijuana use increased among women with this exposure during pregnancy (aOR 2.02 (95\% CI: 1.11, 3.67) (Table 4). The interaction between partnership status and group remained significant (Wald test $p=0.024$ ) in multivariable analyses (Table 5). Among women who were not in a partnership, those in the OUD and OUD + Alcohol groups had significantly lower odds (88.8\% and $91.5 \%$, respectively) of using marijuana relative to the Alcohol group. Among women in the Alcohol only group, partnered women had $87.6 \%$ lower odds of reporting marijuana use than un-partnered women (aOR 0.12; 95\% CI: 0.02, 0.68).

\section{Discussion}

The results of this study indicate a very high proportion (>40\%) of pregnant women, who are in treatment for OUD with or without concurrent alcohol consumption, used marijuana early in pregnancy. These estimates are substantially higher than recent (2017) estimates of past month marijuana use in pregnant and non-pregnant 


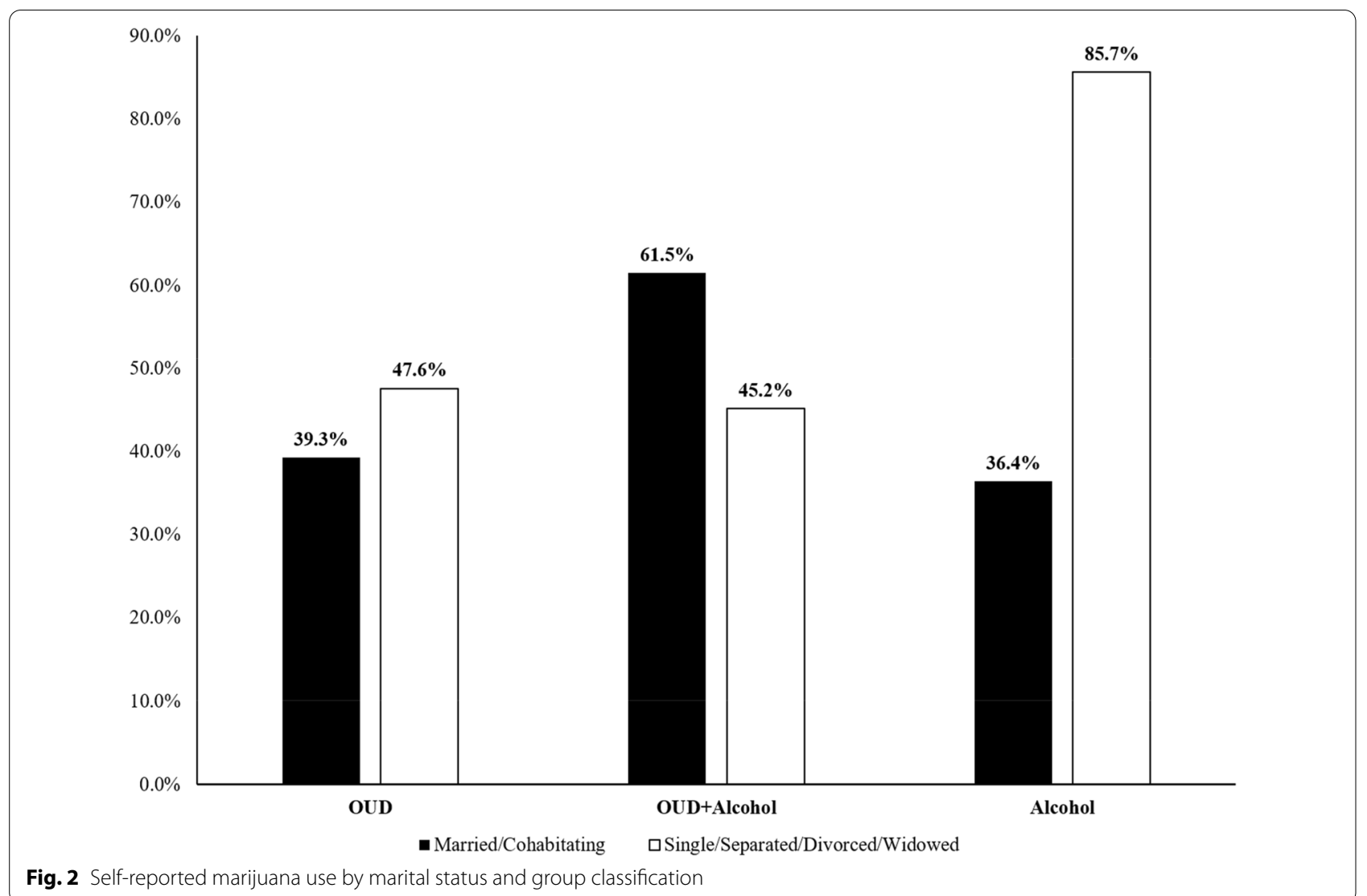

women in the general population surveyed in the NSDUH (7.0\% and $11.2 \%$, respectively [18], and the $3.4 \%$ rate of any use during pregnancy in Northern California [19]). A study in Washington state examined the effect of marijuana legalization on alcohol and drug use in pregnant/parenting women. Subjects were women attending a three-year program serving those who use alcohol and/ or drugs during pregnancy, and the study found women exiting the program in the post-legalization period were twice as likely to report using marijuana in the 30 days before exiting than women in the pre-legalization cohort [24]. Moreover, post-legalization, women were twice as likely to continue use from program enrollment to exit.

Increased marijuana use among pregnant women may be associated with low perceived risk [25, 26]. Women often have contradictory views: on the one hand, trying to decrease use when they become pregnant, but at the same time believing that marijuana is safe, 'natural', and a way to mitigate nausea and vomiting during pregnancy [26-28]. Women report their information sources about marijuana use include non-medical and medical sources $[29,30]$. Some women with OUD also believe marijuana may help manage opioid dependence and withdrawal [31]. The prevalence of marijuana use among pregnant women with OUD and some alcohol use in this study was twice that reported by people with a chronic medical condition surveyed in the 2016 and 2017 Behavioral Risk Factor Surveillance System (BRFSS): $21.9 \%$ of those aged 18-34 with any chronic condition reported marijuana use versus $13.1 \%$ of people surveyed with no medical condition [32]. In general, among people with and without medical conditions, marijuana use has become more acceptable for both recreational and medical reasons; $7.3 \%$ of adult respondents in a national online survey agreed that marijuana use is somewhat or completely safe during pregnancy [33].

In light of the paucity of studies demonstrating safety in pregnancy, particularly concerning is the substantial proportion of women ( $\sim 14 \%$ in both groups) who used marijuana almost daily, as contrasted to $\sim 31 \%$ of patients using once a week or less during pregnancy. It should be noted that women in the Alcohol group reported lightto-moderate/intermittent alcohol use during pregnancy (1.5 drinks/week, on average, 30 days before enrollment).

Interestingly, prevalence estimates were higher per maternal self-report than urinalysis. We attribute this difference to a shorter detection window on urinalysis vs. the reporting timeframe (use between the LMP and 
Table 3 Prevalence of marijuana use during pregnancy by MOUD and other substance exposures stratified by study group ( $\mathrm{N}=251$ )

\begin{tabular}{|c|c|c|c|c|c|c|}
\hline \multirow[t]{3}{*}{ Co-exposures } & \multicolumn{2}{|l|}{ OUD $(n=125)$} & \multicolumn{2}{|c|}{ OUD + alcohol $(n=57)$} & \multicolumn{2}{|l|}{ Alcohol $(n=69)$} \\
\hline & $\begin{array}{l}\text { Marijuana use } \\
(n=54)\end{array}$ & $\begin{array}{l}\text { No Marijuana } \\
\text { use }(n=71)\end{array}$ & $\begin{array}{l}\text { Marijuana use } \\
(\mathrm{n}=30)\end{array}$ & $\begin{array}{l}\text { No Marijuana } \\
\text { use }(n=27)\end{array}$ & $\begin{array}{l}\text { Marijuana use } \\
(n=32)\end{array}$ & $\begin{array}{l}\text { No } \\
\text { marijuana } \\
\text { use }(n=37)\end{array}$ \\
\hline & $\mathrm{n}(\%)$ & $\mathrm{n}(\%)$ & n (\%) & n (\%) & n (\%) & n (\%) \\
\hline \multicolumn{5}{|l|}{ Type of MOUD } & - & - \\
\hline Methadone & $18(37.5)$ & $30(62.5)$ & $9(42.9)$ & $12(57.1)$ & - & - \\
\hline Buprenorphine & $33(45.8)$ & $39(54.2)$ & $21(58.3)$ & $15(41.7)$ & - & - \\
\hline Methadone and buprenorphine & $3(60.0)$ & $2(40.0)$ & $0(0.0)$ & $0(0.0)$ & - & - \\
\hline \multicolumn{7}{|l|}{ Other opioids ${ }^{\mathrm{a}}$} \\
\hline Heroin & $25(49.0)$ & $26(51.0)$ & $14(56.0)$ & $11(44.0)$ & - & - \\
\hline Opioid analgesics ${ }^{b}$ & $16(53.3)$ & $14(46.7)$ & $11(52.4)$ & $10(47.6)$ & $5(55.6)$ & $4(44.4)$ \\
\hline Opiates detected by UDS only & $1(50.0)$ & $1(50.0)$ & $0(0.0)$ & $2(100.0)$ & - & - \\
\hline Polysubstance use $\mathrm{e}^{\mathrm{c}}$ & $25(55.6)$ & $20(44.4)$ & $17(58.6)$ & $12(41.4)$ & $10(58.8)$ & $7(41.2)$ \\
\hline \multirow[t]{2}{*}{ Tobacco use } & $48(47.1)$ & $54(52.9)$ & $27(54.0)$ & $23(46.0)$ & $14(56.0)$ & $11(44.0)$ \\
\hline & Mean (SD) & Mean (SD) & Mean (SD) & Mean (SD) & Mean (SD) & Mean (SD) \\
\hline $\begin{array}{l}\text { Average ounces of alcohol per day, } \\
\text { LMP to Visit } 1^{d}\end{array}$ & $0.0(0.0)$ & $0(0.0)$ & $1.0(1.6)$ & $0.7(1.1)$ & $1.3(2.2)$ & $0.6(1.5)$ \\
\hline AUDIT score ${ }^{1}$ & $1.1(1.7)$ & $0.6(1.0)$ & $11.8(8.4)$ & $15.6(10.9)$ & $14.2(8.1)$ & $10.3(9.0)$ \\
\hline $\begin{array}{l}\text { OUD opioid use disorder, GED General E } \\
\text { a Categories are not mutually exclusive } \\
{ }^{\mathrm{b}} \text { Opioid analgesic use in the Alcohol gr }\end{array}$ & cational Developme & $\begin{array}{l}\text { MOUD medication } \\
\text { sician and did not }\end{array}$ & $\begin{array}{l}\text { ropioid use disorde } \\
\text { nstitute misuse }\end{array}$ & DS urine drug scre & LMP last menstrua & al period \\
\hline \multicolumn{7}{|c|}{$\begin{array}{l}\text { 'Polysubstance use defined as using at least one other substance including: stimulants, benzodiazepines, sedatives, prescription medications (Soma/Carisoprodol), or } \\
\text { hallucinogens }\end{array}$} \\
\hline \multicolumn{7}{|c|}{${ }^{\mathrm{d}}$ Average absolute ounces of alcohol per day across two 30-day timeline follow-back (TLFB) calendars } \\
\hline \multicolumn{7}{|c|}{${ }^{1} p<0.01$ (Wald test from logistic regression model for the interaction between the AUDIT score and group classification) } \\
\hline
\end{tabular}

Table 4 Correlates of marijuana use: results of multivariable logistic regression

\begin{tabular}{lll}
\hline & aOR & $\mathbf{9 5 \% ~ C l}$ \\
\hline Maternal age (5-year increments) & $\mathbf{0 . 6 1}$ & $\mathbf{0 . 4 7 , 0 . 7 9}$ \\
Polysubstance use $^{1}$ & $\mathbf{2 . 0 2}$ & $\mathbf{1 . 1 1}, \mathbf{3 . 6 7}$ \\
Hispanic ethnicity vs. non-hispanic $^{\text {Race }}{ }^{2}$ & 1.24 & $0.65,2.36$ \\
$\quad$ American Indian/Alaska Native vs. White & 1.14 & $0.32,4.15$ \\
$\quad$ Other vs. White & 0.92 & $0.33,2.61$ \\
Education & & \\
$\quad$ <HS vs. $\geq$ College & 0.91 & $0.46,1.80$ \\
$\quad$ HS graduate/GED vs. $\geq$ College & 0.87 & $0.43,1.79$ \\
$\quad$ Tobacco use & 1.80 & $0.88,3.68$ \\
\hline
\end{tabular}

Bold values indicate a statistically significant association

the baseline visit - on average $22.98(\mathrm{SD}=7.09)$ weeks). Urinary elimination of THC might vary depending on the quantity and frequency of marijuana use, creatinine levels, body mass index, and individual differences in metabolism. Typically, a rapid decrease is seen during the first three days of abstinence; however, subjects with high
Table 5 Interaction between partnership status and study group on marijuana use

\begin{tabular}{|c|c|c|c|c|}
\hline & \multicolumn{4}{|c|}{ Partnership status } \\
\hline & \multicolumn{2}{|c|}{$\begin{array}{l}\text { Single/separated/ } \\
\text { divorced/widowed }\end{array}$} & \multicolumn{2}{|c|}{ Married/partnered } \\
\hline & $\mathrm{aOR}$ & $95 \% \mathrm{Cl}$ & aOR & $95 \% \mathrm{Cl}$ \\
\hline OUD & 0.11 & $0.02,0.60$ & 0.68 & $0.28,1.68$ \\
\hline OUD + alcohol & 0.09 & $0.02,0.50$ & 1.45 & $0.49,4.33$ \\
\hline Alcohol & 1.00 & & 1.00 & \\
\hline
\end{tabular}

Bold values indicate a statistically significant association

$a O R$ adjusted odds ratio, GED General Educational Development, OUD opioid use disorder

1 Polysubstance use defined as using at least one other substance including: stimulants, benzodiazepines, sedatives, prescription medications (Soma/ Carisoprodol), or hallucinogens

${ }^{2}$ Due to small frequencies, race was recategorized as White, American Indian/ Alaska Native, Other Race $=$ Black/Multiracial/Other race

exposure levels might have detectable THC concentrations for several weeks [34]. Self-reported measures have the advantage of being noninvasive and enabling evaluation over longer time periods in contrast to biomarker 
assessments. The validity of self-reported drug use can vary by setting, population, and interviewer traits [35]. Validity of self-reported marijuana use has been shown to be high (agreement $81.1 \%$ and sensitivity 91.2\% [36]. And, in drug treatment settings, self-reported opioid use has been shown to be high (sensitivity 99\%) [37]. We have previously shown that pregnant women in a substance use treatment program generally under-report substance use, but opioids and marijuana are more accurately reported [38]. Specifically, sensitivity of self-report was $100 \%$ for methadone, $83.3 \%$ for buprenorphine, $58.3 \%$ for other opioids, and $57.9 \%$ for marijuana as opposed to amphetamines (37.5\%), benzodiazepines (40\%), and cocaine $(47.4 \%)$ [38].

Younger maternal age, using other substances, and partnership status were independently associated with marijuana use in our study, consistent with other studies $[18,19]$. Un-partnered women with OUD, with and without alcohol use during pregnancy, demonstrated a lower prevalence of marijuana use compared to women who just used alcohol alone. We observed, among women who were partnered (married or cohabitating), those with a history of both OUD and alcohol use were more likely to use marijuana than women who used alcohol alone. Few studies have examined marijuana use among pregnant women who have used other substances; however, our findings differ from other studies of pregnant women, wherein married women were less likely to use marijuana [25, 39] or opioids [40] compared to unpartnered (unmarried, divorced, separated, or widowed) women. Differences in marijuana use by marital status may be related to reasons for use, such as recreational, medical, or ease of access. In a study examining alcohol use in cannabis users (with and without a medical recommendation) Subbaraman et al. [41] found no differences in cannabis use by marital status. Partnership factors are known to influence substance use patterns. Some studies have found newly married men and women tend to reduce substance use over time [42, 43]. However, women in relationships with drug-using men may be more likely to use and misuse substances $[44,45]$. Our findings point to the need to examine social factors specific to marijuana use in pregnant women with a history of substance and/or alcohol use.

Women in our study demonstrated a high prevalence of polysubstance use (36.3\%), which is consistent with other reports $[25,40]$, and marijuana use was over twice as likely for women who reported polysubstance use in comparison to women who did not report polysubstance use. Concurrent tobacco use was particularly high $(70.5 \%)$ in all women, and both tobacco and estimated alcohol consumption were higher among those who concurrently used marijuana. A study of over 160,000 pregnant women admitted for substance use treatment demonstrated that alcohol and marijuana were the most common co-exposures [46]. Polysubstance use is of significant concern among pregnant women. We have previously shown that the risk of growth deficiencies (i.e., head circumference $<10^{\text {th }}$ percentile) was substantially increased in polydrug users compared to abstinent controls [47]. Additionally, polysubstance exposure was found to be the most significant predictor of NOWS severity in buprenorphine-exposed neonates [48].

The findings of this analysis should be interpreted in light of several limitations. First, while the sample size of this study was large (251 participants), results cannot be generalized to all pregnant women who use substances in pregnancy since the patients were recruited from a comprehensive multi-disciplinary prenatal clinic at UNM focused on SUD. Further, results cannot be generalized to patients with OUD who do not receive MOUD who may have even higher rates of marijuana use. Second, we could not examine secular trends in the prevalence of marijuana use over time. In New Mexico, medical marijuana use was legalized in 2007, while recreational use remained illegal but was decriminalized in 2019. (In early 2021, recreational use was legalized.) Thus, since most data were obtained before 2019, estimates are likely to be conservative. Third, we acknowledge a relatively small sample size in the OUD + Alcohol and Alcohol groups and limited generalizability to patients with different alcohol consumption patterns, including women with alcohol use disorder. Strengths of the study include a prospective cohort design and state-of-the-art characterization of prenatal substance use with repeated prospective interviews and comprehensive batteries of biomarkers for alcohol, tobacco, and illicit drug use.

Future studies should specifically examine the prevalence of marijuana use in pregnant women with chronic use of opioid analgesics and those with OUD who are not receiving methadone or buprenorphine. Opioid use disorder has been listed (since 2018 and not overlapping with enrollment in this study) as one of the 28 indications for medical marijuana in New Mexico, and pregnancy is not an exclusion criteria, which may result in pregnant woman with OUD continuing or initiating medical marijuana [49]. Given the unique impact of the opioid epidemic on rural/under-served areas, it would be important to characterize the pattern of substance use in rural vs. urban areas and examine trends and motivations over time and as a function of marijuana legalization laws. A new preclinical research finding indicates that simultaneous exposure to alcohol and cannabinoid compounds increases the risk of birth defects in a murine model, indicative of a compounding interaction [50]. This research also demonstrated 
common signaling pathways for such interactive effects on fetal mice development. Future studies of adverse perinatal and pediatric neurodevelopmental outcomes associated with intrauterine exposure to opioids and alcohol need to characterize marijuana co-exposure carefully, given the potential additive effects.

The American College of Obstetricians and Gynecologists (ACOG) recommends that pregnant women "reporting marijuana use should be counseled about concerns regarding potential adverse health consequences of continued use during pregnancy... [and] should be encouraged to discontinue marijuana use" [51]. While little is known about the direct effects of marijuana use on the developing brain (based on restricted access to marijuana for research studies), cannabinoid receptors are found throughout the brain, and the scant work that has been performed demonstrates broad alterations to brain function with cannabinoid exposure [52-55]. As legalization of marijuana becomes more widespread and the percentage of THC in marijuana products continues to increase, additional information about the effects of prenatal marijuana exposure will need to be obtained. Moreover, ACOG also recommends that alternative therapeutic approaches with better pregnancy-specific safety data be considered instead of medical marijuana use. The American Academy of Pediatrics (AAP) also advises against the use of marijuana or other cannabinoidcontaining products either for recreational or medical reasons, including nausea and vomiting during pregnancy. AAP recommends universal screening, brief intervention, and referral for treatment [56]. Currently, the ACOG, AAP and the Surgeon General recommend women to abstain from marijuana use completely if they are trying to conceive, pregnant or lactating. There remain significant gaps in knowledge and research however. For instance, there is not substantial data to conclude that abstinence from marijuana use will decrease negative perinatal/pediatric outcomes as it does for cigarette [57] and alcohol exposure [58]. Nevertheless, a harm reduction approach would include consideration of decreasing use in the high proportion of women with near-daily use.

\section{Conclusions}

Results of this study indicate a high prevalence of marijuana use in pregnant women receiving MOUD and non-abstainers of alcohol during pregnancy, and a high proportion of these women use marijuana regularly. Our findings are concerning due to the risks of polysubstance use to both mother and fetus. Further research and evaluation of programs to reduce marijuana use in pregnant women, especially those with OUD or who engage in alcohol consumption, are needed.

\section{Abbreviations}

AAP: American Academy of Pediatrics; ACOG: American College of Obstetricians and Gynecologists; aOR: Adjusted odds ratio; BRFSS: Behavioral Risk Factor Surveillance System; Cl: Confidence intervals; GGT: Gamma-glutamyl transpeptidase; LMP: Last menstrual period; MDMA: Methylenedioxymethamphetamine; MOUD: Medications for the treatment of opioid use disorder; MOUD: Medications for the treatment of OUD; NIH: National Institutes of Health; NOWS: Neonatal opioid withdrawal syndrome; NSDUH: National Survey on Drug Use and Health; OUD: Opioid use disorder; PCP: Phencyclidine or phenylcyclohexyl piperidine; SUD: Substance use disorders; THC: Tetrahydrocannabinol; TLFB: Timeline Follow-back Calendars; UDS: Urine drug screen; UNM: University of New Mexico.

\section{Acknowledgements}

We would like to acknowledge the assistance of Dr. Shikhar Shrestha (currently with the Tufts University School of Medicine, formerly at the University of New Mexico), Yuridia Leyva, Dominique Rodriguez, and Lidia Enriquez Marquez (all of University of New Mexico Health Sciences Center) with data collection, data management, and preliminary analyses. All of these individuals were supported by the NIH grant R01 AA021771. We also thank Brooke Zeno for editorial review.

\section{Authors' contributions}

All authors contributed substantially to this paper. LNB and JMS conceptualized and desigbned the parent study (ENRICH-1 Cohort) and with $L L$ the acquisition of data. KP conceptualized the research question in this paper. CM-K and MC led data analyses. All authors (KP, CM-K, LL, MC, MC and LNB) contributed to interpretation of the data and drafting the manuscript. All authors reviewed and have approved the final manuscript.

\section{Funding}

This research was supported by the National Institute on Alcohol Abuse and Alcoholism (research Grant R01 AA021771) and the National Institute on Drug Abuse (research Grant 1R34DA050237) of the National Institutes of Health $(\mathrm{NIH})$. The NIH did not play any role in the study design, conclusions, analysis and interpretation of data, writing of the report, or the decision to submit the article for publication. Dr. Page was supported by UNM Clinical and Translational Science Center (1UL TR001449).

\section{Declarations}

\section{Ethics approval and consent to participate}

The study was approved by the UNM Human Research Review Committee (protocol: 12-390);; all participants provided signed informed consent.

\section{Consent for publication}

Not applicable.

\section{Availability of data and materials}

The datasets generated and/or analyzed during the current study are not publically available due to lack of data sharing acknowledgement of de-identified data in the consent and IRB protocol. The request for data sharing can be considered on a case-by-case b asis with a formal data sharing agreement between institutions.

\section{Competing interests}

The authors declaure they have no competing interests. 


\section{Author details}

${ }^{1}$ Division of Epidemiology, Biostatistics and Preventive Medicine, Department of Internal Medicine, School of Medicine, University of New Mexico MSC 10 5550, Albuquerque, NM 87131, USA. ${ }^{2}$ Department of Family and Community Medicine, School of Medicine, University of New Mexico, Albuquerque, NM, USA. ${ }^{3}$ Department of Obstetrics and Gynecology, School of Medicine, University of New Mexico, Albuquerque, NM, USA. ${ }^{4}$ The Mind Research Network a Division of Lovelace Biomedical Research Institute, Albuquerque, NM, USA. ${ }^{5}$ Department of Pharmacy Practice and Administrative Sciences, Substance Use Research and Education (SURE) Center, College of Pharmacy, University of New Mexico, Albuquerque, NM, USA.

Received: 7 June 2021 Accepted: 17 December 2021

Published online: 06 January 2022

\section{References}

1. Desai RJ, Hernandez-Diaz S, Bateman BT, Huybrechts KF. Increase in prescription opioid use during pregnancy among Medicaid-enrolled women. Obstet Gynecol. 2014;123(5):997-1002.

2. Kozhimannil KB, Graves AJ, Levy R, Patrick SW. Nonmedical use of prescription opioids among pregnant U.S. women. Womens Health Issues. 2017;27(3):308-15.

3. Haight SC, Ko JY, Tong VT, Bohm MK, Callaghan WM. Opioid use disorder documented at delivery hospitalization-United States, 1999-2014. MMWR Morb Mortal Wkly Rep. 2018;67(31):845-9.

4. Saavedra LG. Neonatal abstinence syndrome surveillance in New Mexico. New Mexico Epidemiology Volume 2018, Number 10 November 30, 2018. https://nmhealth.org/data/view/report/2194/. Accessed 27 Nov 2019.

5. Yazdy MM, Desai RJ, Brogly SB. Prescription opioids in pregnancy and birth outcomes: a review of the literature. J Pediatr Genet. 2015;4(2):56-70.

6. Kaltenbach K, O'Grady KE, Heil SH, Salisbury AL, Coyle MG, Fischer G, Martin PR, Stine S, Jones HE. Prenatal exposure to methadone or buprenorphine: early childhood developmental outcomes. Drug Alcohol Depend. 2018;185:40-9.

7. Bakhireva LN, Holbrook BD, Shrestha S, Leyva Y, Ashley M, Cano S, Lowe J, Stephen JM, Leeman L. Association between prenatal opioid exposure, neonatal opioid withdrawal syndrome, and neurodevelopmental and behavioral outcomes at 5-8 months of age. Early Human Dev. 2019;128:69-76.

8. Shrestha S, Roberts MH, Maxwell JR, Leeman LM, Bakhireva LN. Post-discharge healthcare utilization in infants with neonatal opioid withdrawal syndrome. Neurotoxicol Teratol. 2021;86:106975.

9. Riley EP, Infante MA, Warren KR. Fetal alcohol spectrum disorders: an overview. Neuropsychol Rev. 2011;21(2):73-80.

10. Bakhireva LN, Shrestha S, Garrison L, Leeman L, Rayburn WF, Stephen JM. Prevalence of alcohol use in pregnant women with substance use disorder. Drug Alcohol Depend. 2018;187:305-10.

11. El Marroun H, Bolhuis K, Franken IHA, Jaddoe VWV, Hillegers MH, Lahey $\mathrm{BB}$, Tiemeier $\mathrm{H}$. Preconception and prenatal cannabis use and the risk of behavioural and emotional problems in the offspring; a multi-informant prospective longitudinal study. Int J Epidemiol. 2018;48:287-96.

12. El Marroun H, Hudziak JJ, Tiemeier H, Creemers H, Steegers EA, Jaddoe VW, Hofman A, Verhulst FC, van den Brink W, Huizink AC. Intrauterine cannabis exposure leads to more aggressive behavior and attention problems in 18-month-old girls. Drug Alcohol Depend. 2011;118(2-3):470-4.

13. MetzTD, Allshouse AA, Hogue CJ, Goldenberg RL, Dudley DJ, Varner MW, Conway DL, Saade GR, Silver RM. Maternal marijuana use, adverse pregnancy outcomes, and neonatal morbidity. Am J Obstetr Gynecol. 2017;217(4):478e471-8

14. Narendran N, Yusuf K. Marijuana use during pregnancy and lactation and long-term outcomes. NeoReviews. 2021;22(8):e521-30.

15. O'Connor AB, Kelly BK, O'Brien LM. Maternal and infant outcomes following third trimester exposure to marijuana in opioid dependent pregnant women maintained on buprenorphine. Drug Alcohol Depend. 2017;180:200-3.
16. Skelton KR, Hecht AA, Benjamin-Neelon SE. Association of recreational cannabis legalization with maternal cannabis use in the preconception, prenatal, and postpartum periods. JAMA Netw Open. 2021;4(2):e210138.

17. Brown QL, Sarvet AL, Shmulewitz D, Martins SS, Wall MM, Hasin DS. Trends in marijuana use among pregnant and nonpregnant reproductive-aged women, 2002-2014. JAMA. 2017;317(2):207-9.

18. Volkow ND, Han B, Compton WM, McCance-Katz EF. Self-reported medical and nonmedical cannabis use among pregnant women in the United States. JAMA. 2019:322(2):167-9.

19. Young-Wolff KC, Sarovar V, Tucker LY, Conway A, Alexeeff S, Weisner C, Armstrong MA, Goler N. Self-reported daily, weekly, and monthly cannabis use among women before and during pregnancy. JAMA Netw Open. 2019;2(7):e196471.

20. Meinhofer A, Witman A, Murphy SM, Bao Y. Medical marijuana laws are associated with increases in substance use treatment admissions by pregnant women. Addiction (Abingdon, England). 2019;114(9):1593-601.

21. Bakhireva LN, Lowe JR, Gutierrez HL, Stephen JM. Ethanol, Neurodevelopment, Infant and Child Health (ENRICH) prospective cohort: study design considerations. Adv Pediatr Res. 2015;2015:2.

22. Jacobson SW, Chiodo LM, Sokol RJ, Jacobson JL. Validity of maternal report of prenatal alcohol, cocaine, and smoking in relation to neurobehavioral outcome. Pediatrics. 2002;109(5):815-25.

23. National Survey on Drug Use and Health: ICPSR 34481-v3. Ann Arbor (MI): US Department of Health and Human Services, Substance Abuse and Mental Health Services Administration. Center for Behavioral Health Statistics and Quality; 2011.

24. Grant TM, Graham JC, Carlini BH, Ernst CC, Brown NN. Use of marijuana and other substances among pregnant and parenting women with substance use disorders: changes in washington state after marijuana legalization. J Stud Alcohol Drugs. 2018;79(1):88-95.

25. Ko JY, Farr SL, Tong VT, Creanga AA, Callaghan WM. Prevalence and patterns of marijuana use among pregnant and nonpregnant women of reproductive age. Am J Obstet Gynecol. 2015;213(2):201.e201-201. e210.

26. Chang JC, Tarr JA, Holland CL, De Genna NM, Richardson GA, Rodriguez KL, Sheeder J, Kraemer KL, Day NL, Rubio D, et al. Beliefs and attitudes regarding prenatal marijuana use: perspectives of pregnant women who report use. Drug Alcohol Depend. 2019;196:14-20.

27. Roberson EK, Patrick WK, Hurwitz EL. Marijuana use and maternal experiences of severe nausea during pregnancy in Hawai'i. Hawaii J Med Public Health. 2014;73(9):283-7.

28. Young-Wolff KC, Conway A, Goler N. Why pregnant women may justifiably choose to use cannabis-reply. JAMA Intern Med. 2019;179(1):120-1.

29. Committee on Obstetric P. Committee Opinion No. 722: Marijuana use during pregnancy and lactation. Obstetr Gynecol. 2017;130(4):e205-e209.

30. Jarlenski M, Tarr JA, Holland CL, Farrell D, Chang JC. Pregnant women's access to information about perinatal marijuana use: a qualitative study. Womens Health Issues. 2016;26(4):452-9.

31. Clem SN, Bigand TL, Wilson M. Cannabis use motivations among adults prescribed opioids for pain versus opioid addiction. Pain Manag Nurs. 2019;21:43

32. Dai H, Richter KP. A National Survey of Marijuana use among us adults with medical conditions, 2016-2017. JAMA Netw Open. 2019;2(9):e1911936.

33. Keyhani S, Steigerwald S, Ishida J, Vali M, Cerda M, Hasin D, Dollinger C, Yoo SR, Cohen BE. Risks and benefits of marijuana use: a national survey of U.S. adults. Ann Intern Med. 2018;169(5):282-90.

34. Goodwin RS, Darwin WD, Chiang CN, Shih M, Li SH, Huestis MA. Urinary elimination of 11-nor-9-carboxy-delta9-tetrahydrocannnabinol in cannabis users during continuously monitored abstinence. J Anal Toxicol. 2008;32(8):562-9.

35. Harrison $L$. The validity of self-reported drug use in survey research: an overview and critique of research methods. NIDA Res Monogr. 1997;167:17-36.

36. Buchan BJ, Dennis ML, Tims FM, Diamond GS. Cannabis use: consistency and validity of self-report, on-site urine testing and laboratory testing. Addiction (Abingdon, England). 2002;97(Suppl 1):98-108. 
37. Sherman MF, Bigelow GE. Validity of patients' self-reported drug use as a function of treatment status. Drug Alcohol Depend. 1992;30(1):1-11.

38. Garg M, Garrison L, Leeman L, Hamidovic A, Borrego M, Rayburn WF, Bakhireva L. Validity of self-reported drug use information among pregnant women. Matern Child Health J. 2016;20(1):41-7.

39. Oh S, Salas-Wright CP, Vaughn MG, DiNitto DM. Marijuana use during pregnancy: a comparison of trends and correlates among married and unmarried pregnant women. Drug Alcohol Depend. 2017;181:229-33.

40. Elliott TE, Frail CK, Pawloski PA, Thomas AJ, Werner AM, Rossom RC. Opioid use during pregnancy, observations of opioid use, and secular trend from 2006 to 2014 at HealthPartners Medical Group. Clin J Pain. 2018;34(8):707-12.

41. Subbaraman MS, Kerr WC. Alcohol use and risk of related problems among cannabis users is lower among those with medical cannabis recommendations, though not due to health. J Stud Alcohol Drugs. 2018;79(6):935-42.

42. Duncan GJ, Wilkerson B, England P. Cleaning up their act: the effects of marriage and cohabitation on licit and illicit drug use. Demography. 2006;43(4):691-710.

43. Merline AC, Schulenberg JE, O'Malley PM, Bachman JG, Johnston LD. Substance use in marital dyads: premarital assortment and change over time. J Stud Alcohol Drugs. 2008;69(3):352-61.

44. Fals-Stewart W, Birchler GR, O'Farrell TJ. Drug-abusing patients and their intimate partners: dyadic adjustment, relationship stability, and substance use. J Abnorm Psychol. 1999;108(1):11-23.

45. Rhodes T, Rance J, Fraser S, Treloar C. The intimate relationship as a site of social protection: partnerships between people who inject drugs. Soc Sci Med. 2017;180:125-34.

46. Washio Y, Martin CE, Goldstein ND, Terplan M. Characteristics of pregnant women who reported alcohol use at admission to substance use treatment. J Subst Abuse Treat. 2017;82:82-6.

47. Garrison L, Leeman L, Savich RD, Gutierrez H, Rayburn WF, Bakhireva LN. Fetal growth outcomes in a cohort of polydrug- and opioid-dependent patients. J Reprod Med. 2016;61(7-8):311-9.

48. Jansson LM, Velez ML, McConnell K, Spencer $\mathrm{N}$, Tuten M, Jones $H$, Rios R King VL, Gandotra N, Millio L, et al. Maternal buprenorphine treatment and infant outcome. Drug Alcohol Depend. 2017;180:56-61.

49. New Mexico Department of Health: Medical Cannabis Program. https:// nmhealth.org/about/mcp/svcs/info/. Accessed 27 Nov 2019.

50. Fish EW, Murdaugh LB, Zhang C, Boschen KE, Boa-Amponsem O, Mendoza-Romero HN, Tarpley M, Chdid L, Mukhopadhyay S, Cole GJ, et al. Cannabinoids exacerbate alcohol teratogenesis by a CB1-Hedgehog Interaction. Sci Rep. 2019;9(1):16057.

51. American College of Obstetricians and Gynecologists: Marijuana use during pregnancy and lactation. ACOG Committee Opinion. Interim Update October 2017; reaffirmed 2019. . https://www.acogorg/Clinical-Guida nce-and-Publications/Committee-Opinions/Committee-on-ObstetricPractice/Marijuana-Use-During-Pregnancy-and-Lactation?lsMobileSet= false Accessed 28 Nov 2019.

52. Metz TD, Borgelt LM. Marijuana use in pregnancy and while breastfeeding. Obstet Gynecol. 2018;132(5):1198-210.

53. Cohen K, Weizman A, Weinstein A. Modulatory effects of cannabinoids on brain neurotransmission. Eur J Neurosci. 2019;50(3):2322-45.

54. Mohiuddin M, Blyth FM, Degenhardt L, Di Forti M, Eccleston C, Haroutounian S, Moore A, Rice ASC, Wallace M, Park R, et al. General risks of harm with cannabinoids, cannabis, and cannabis-based medicine possibly relevant to patients receiving these for pain management: an overview of systematic reviews. Pain. 2021;162(Suppl 1):S80-96.

55. Badowski S, Smith G. Cannabis use during pregnancy and postpartum. Can Fam Physician. 2020;66(2):98-103.

56. Ryan SA, Ammerman SD, O'Connor ME, Committee On Substance USE, Prevention, Section On B. Marijuana use during pregnancy and breastfeeding: implications for neonatal and childhood outcomes. Pediatrics. 2018;142(3).

57. Marufu TC, Ahankari A, Coleman T, Lewis S. Maternal smoking and the risk of still birth: systematic review and meta-analysis. BMC Public Health. 2015; 15:239.

58. Kesmodel U, Wisborg K, Olsen SF, Henriksen TB, Secher NJ. Moderate alcohol intake during pregnancy and the risk of stillbirth and death in the first year of life. Am J Epidemiol. 2002;155(4):305-12.

\section{Publisher's Note}

Springer Nature remains neutral with regard to jurisdictional claims in published maps and institutional affiliations.
Ready to submit your research? Choose BMC and benefit from:

- fast, convenient online submission

- thorough peer review by experienced researchers in your field

- rapid publication on acceptance

- support for research data, including large and complex data types

- gold Open Access which fosters wider collaboration and increased citations

- maximum visibility for your research: over $100 \mathrm{M}$ website views per year

At BMC, research is always in progress.

Learn more biomedcentral.com/submissions 